\title{
MULTIPLE DEFECT DISTRIBUTIONS ON WEIBULL STATISTICAL ANALYSIS OF FATIGUE LIFE OF CAST ALUMINIUM ALLOYS
}

\author{
Nyahumwa, C. \\ Department of Engineering Materials, University of Dar es Salaam, Tanzania \\ P.O. Box 53131, Dar es Salaam, Tanzania
}

\begin{abstract}
From an engineering point of view, the fatigue strength variability of cast aluminium alloy components requires a detailed understanding of the inconsistency of cast defect distribution. Cast aluminium alloys are not generally homogeneous; they may contain two or more types of common casting defects, which are gas and shrinkage porosities, oxide films, and inclusions. Each defect type has its own distribution of sizes; and multiple cast components of presumably the same material may have different histories and therefore different cast defect populations. A number of statistical analyses of fatigue data assume that a single distribution of casting defect is present uniformly throughout the cast aluminium alloys. As a result, fatigue data are statistically not correctly described. By relaxing the assumptions of a single cast defect distribution, of uniformity throughout the material and of uniformity from specimen to specimen, Weibull statistical analysis for multiple defect distributions have been applied to correctly describe the fatigue life data of aluminium alloy castings having multiple cast defects competing to initiate fatigue cracks.
\end{abstract}

Keywords: Casting defects; Aluminium alloys; Weibull analysis; Fatigue data

\section{INTRODUCTION}

Cast aluminium alloys are often considered to be unreliable in view of their mechanical properties due to presence of a variety of casting defects. Consequently, design stresses in the castings are usually very low compared with those allowed in forgings [1]. This poor reputation is partly because of bad foundry practice which can lead to the occurrence of gross defects such as shrinkage and gas porosity $[2,3]$ or to entrapped dross and oxide films in castings $[1,2,4]$. Two or more of these defects may be contained in castings and compete to influence fatigue strength of the castings as well as make the interpretation of fatigue data difficult.

The ability to predict fatigue failure of aluminium alloy castings at various stresses is hindered by an incomplete knowledge of the exact mechanisms generating fatigue cracks among the multiple defects present in the castings and causing failure. There is need therefore to acquire a detailed understanding of the variability in multiple defect types and their influence on fatigue strength of cast aluminium alloys.
Weibull distribution functions $[5,6]$ are therefore used to quantitatively illustrate some consequences of various stages of multiple defect distributions on fatigue life of cast aluminium alloys.

\section{REVIEW OF WEIBULLSTATISTICAL DISTRIBUTIONS}

The majority of the statistical descriptions of fatigue data presently available are based on the weakest link concept. The concept simply states that the entire body will fail when the stress at any defect is sufficient for unstable crack propagation of the defect. Examples of weakest link distribution functions are the Weibull distribution $[5,6]$, and the three extreme value distributions [7, 8]. Although a universally acceptable distribution function has not been identified, the Weibull distribution has become very popular and frequently been applied. This is due to its mathematical simplicity and the relatively good success in describing most fatigue data. 
Most statistical descriptions of fatigue life of materials assume that a single distribution of flaws is present uniformly throughout the material and multiple castings of the same material contain the same flaw (defect). Twoparameter Weibull statistical distribution as expressed in equation (1) is normally applied [5].

$F_{w}(N)=1-\exp \left[-\left(\frac{N}{N_{c}}\right)^{b}\right]$

where, $F_{w}(N)$ is statistical fraction of specimens that failed at given cycles, $N$, or lower, $N$ is number of cycles to failure, $N_{c}$ is characteristic life (cycles when approximately $63.2 \%$ of specimens have failed), $b$ is Weibull slope or modulus (shape parameter).

Less frequently, three-parameter Weibull statistical distribution as expressed in equation (2) is applied in describing fatigue data.

$F_{w}(N)=1-\exp \left[-\left(\frac{N-N_{l}}{N_{c}-N_{l}}\right)^{b}\right]$

where, $N_{l}=$ number of cycles below which no specimens failed (location parameter).

However, multiple defect distributions have been recently observed to affect the fracture strength of brittle materials such as ceramics, which cannot correctly be statistically described by single Weibull distribution models (Equations (1) and (2)) [6]. Likewise, in this study, multiple casting defects have been observed to influence the fatigue strength of aluminium alloy castings. There is need therefore to investigate Weibull distribution models which can correctly describe fatigue life of castings failed from fatigue cracks initiated from multiple casting defects. Various Weibull statistical models, which are considered for the analysis of fatigue life results obtained in this study, are reviewed for different types of distributions in materials.

\section{Concurrent defect distributions in materials}

A group of engineering components from which all the components have two independent means of failure, defect type $A$ and defect type $B$, is said to contain 'concurrent' defect distribution. If the two-parameter Weibull distribution, as given in equation (2), is valid for both defect populations, the cumulative probability of failure $F_{w}$, as described from weakest link theory [3], for any specimen becomes:

$F_{w}(N)=1-\exp \left[-\left(\frac{N}{N_{A}}\right)^{b_{A}}-\left(\frac{N}{N_{B}}\right)^{b_{B}}\right]$ where, $N_{A}$ and $N_{B}$ are characteristic lives for specimens failed from defect types $A$ and $B$, respectively, $b_{A}$ and $b_{B}$ are Weibull moduli for specimens failed from defect types $A$ and $B$, respectively.

The failure probability function as shown in equation (3) contains four adjustable parameters, $b_{A}, N_{A}, b_{B}$, and $N_{B}$. Each additional concurrent defect distribution adds another term to the exponential, and an additional two adjustable parameters.

\section{Mutually exclusive defect distributions in materials}

Within a group of specimens any given specimen may contain defects either from distribution, $A$, or from distribution, $B$, but not from both. In this group the means of failure from defect type $A$ and defect type $B$ is referred as an 'exclusive' defect distribution. If the two-parameter Weibull distribution is valid for both distributions then equation (4) becomes:

$F_{w}(N)=1-(1-a) \exp \left[-\left(\frac{N}{N_{A}}\right)^{b_{A}}\right]-a \exp \left[-\left(\frac{N}{N_{B}}\right)^{b_{B}}\right]$

where, $(1-a)$ is a fraction (probability of occurrence) of specimens containing only defects from distribution $A, a$ is a fraction (probability of occurrence) of specimens containing only defects from distribution $B$.

\section{Partially concurrent defect distributions in material}

For a group of specimens or components from which all specimens contain one defect distribution but only a fraction contain the other, the group is said to contain 'partially concurrent' defect distributions. The mathematics of partially concurrent distributions is best described by considering two mutually exclusive states. A specimen either contains distribution defect $A$ alone or it contains both distributions, $A$ and $B$, in concurrent manner. The fraction of specimens in the second state is $a$, therefore the fraction in the first state must be $1-a$. If the two-parameter Weibull distribution is valid for both defect populations, the cumulative probability of failure, $F_{W}$ for partially concurrent defect distribution becomes [6]:

$F_{w}(N)=1-(1-a) \exp \left[-\left(\frac{N}{N_{A}}\right)^{b_{A}}\right]-a \exp \left[-\left(\frac{N}{N_{A}}\right)^{b_{A}}-\left(\frac{N}{N_{B}}\right)^{b_{B}}\right]$ 


\section{MATERIALANDEXPERIMENTAL PROCEDURES}

The material used in this study was an Al-7Si-Mg alloy (2L99) with the chemical composition: $7.25 \% \mathrm{Si}, 0.33 \%$ $\mathrm{Mg}, 0.02 \% \mathrm{Cu}, 0.14 \% \mathrm{Fe}, 0.03 \% \mathrm{Mn}, 0.01 \% \mathrm{Ni},<0.01 \% \mathrm{Zn}$, $0.01 \% \mathrm{~Pb},<0.01 \% \mathrm{Sn}, 0.12 \% \mathrm{Ti}$ and $\mathrm{Al}-$ balance.

To ensure the inherent variability of casting processes normally found in foundry industry, two-gravity filling systems were used to produce cast test bars. The first type of mould filling system was bottom filling through a poorly designed running system resulting in some surface turbulence. The second type of mould filling system was bottom filling through a filter at an initial runner velocity of less than $0.5 \mathrm{~ms}^{-1}$ beyond the filter, producing turbulence free conditions.

The as-cast test bars were subjected to identical T6 heat treatment cycles which comprised solution heat treatment at $540^{\circ} \mathrm{C}$ for 6 hours, then quenching in water at room temperature. The specimens were then artificially aged at $160^{\circ} \mathrm{C}$ for 5 hours and left to cool in still air.

High cycle fatigue (HCF) life test was conducted using an Amsler Vibrophore machine. The specimens were cycled in alternating tension-tension with stress ration $\mathrm{R}=+0.1$. On so doing the specimen was kept in tension throughout the fatigue test, thereby avoiding damage to the fatigue surface and initiator by closure of the crack. Thirty-two bottom-filled filtered and thirty-two unfiltered cast specimens were randomly selected and tested at a maximum stress of $150 \mathrm{MPa}$.

Defects responsible for fatigue crack initiation were systematically examined on fatigue fracture surfaces of all failed specimens to establish their types using scanning electron microscope (SEM).

\section{RESULTS AND DISCUSSION}

\section{Susceptibility of mould filling systems on multiple casting defect variability}

As can be seen in Figure 1, there is a significant difference between the fatigue life distribution of the unfiltered castings and that of the filtered castings. These results clearly indicate that the two mould filling methods had different propensities on the generation of casting defects, which subsequently initiated fatigue cracks. This is a reflection of what is being expected in foundry industry practice.

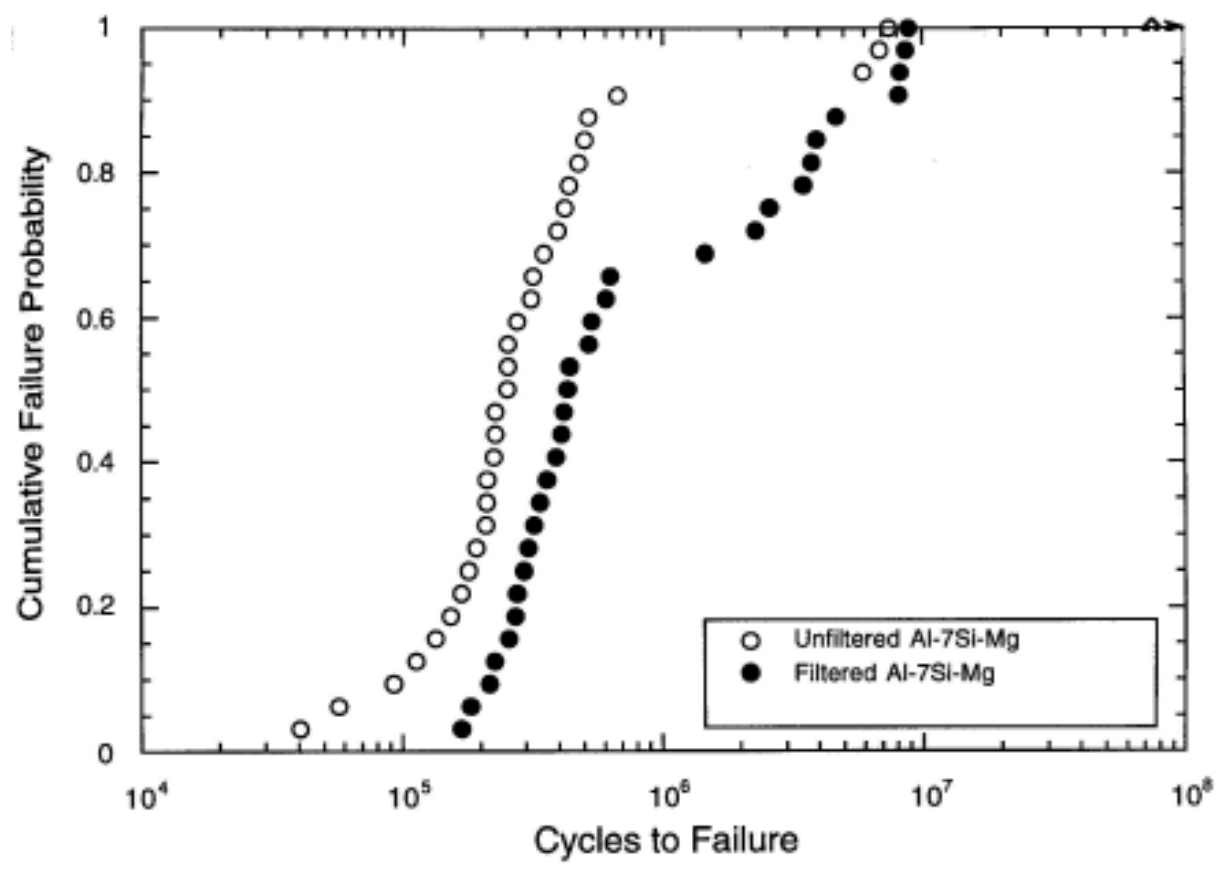

Figure 1: Fatigue life distributions for bottom-filled unfiltered and filtered castings 
Based on the fractographic identification of fatigue crack initiators the different types of inherent defects were found to play different roles in determining the fatigue life of Al7Si-Mg alloy castings. The variation in life was governed by their effectiveness as crack initiators. For example in unfiltered castings, fatigue cracks initiated at young oxide film defects (Figure 2) and at gas pores (Figure 3), which were associated with lower fatigue lives. This contrasts with the results in filtered castings where the fatigue cracks frequently initiated by old oxide film defects (Figure 4), which were associated with higher fatigue lives.

Figure 5 shows that for any fatigue life less than or equal to $7 \times 10^{5}$ cycles both filtered and unfiltered castings failed from fatigue cracks initiated by oxide film defects. Above this fatigue life the fatigue failures were initiated as a result of slip mechanisms. These are the two distinct regions of fatigue crack initiators which have been found to be common to both fatigue life data sets. However, the slip mechanisms were found to operate more in the filtered castings indicating that overall the defect density in the liquid metal was lower. It was also observed that the old oxides acted as fatigue crack initiators in both unfiltered and filtered castings, but the young oxide film defects, and pores attached to oxide films, were only found to act as fatigue crack initiators in the unfiltered castings.

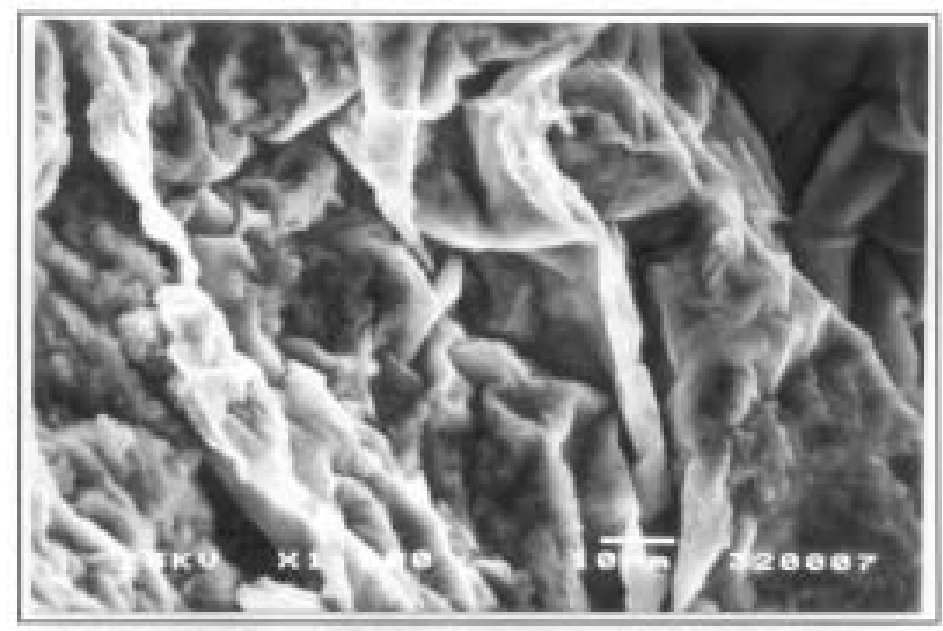

Figure 2: Secondary electron micrograph showing young oxide film defect initiated fatigue crack in unfiltered casting

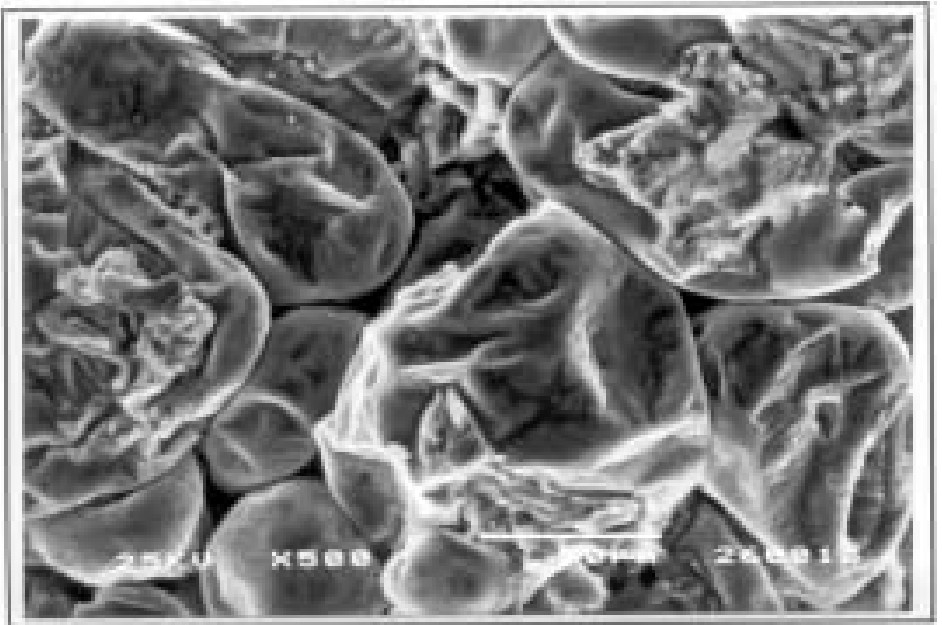

Figure 3: Secondary electron micrograph showing a pore attached to oxide film initiated fatigue crack in unfiltered casting 


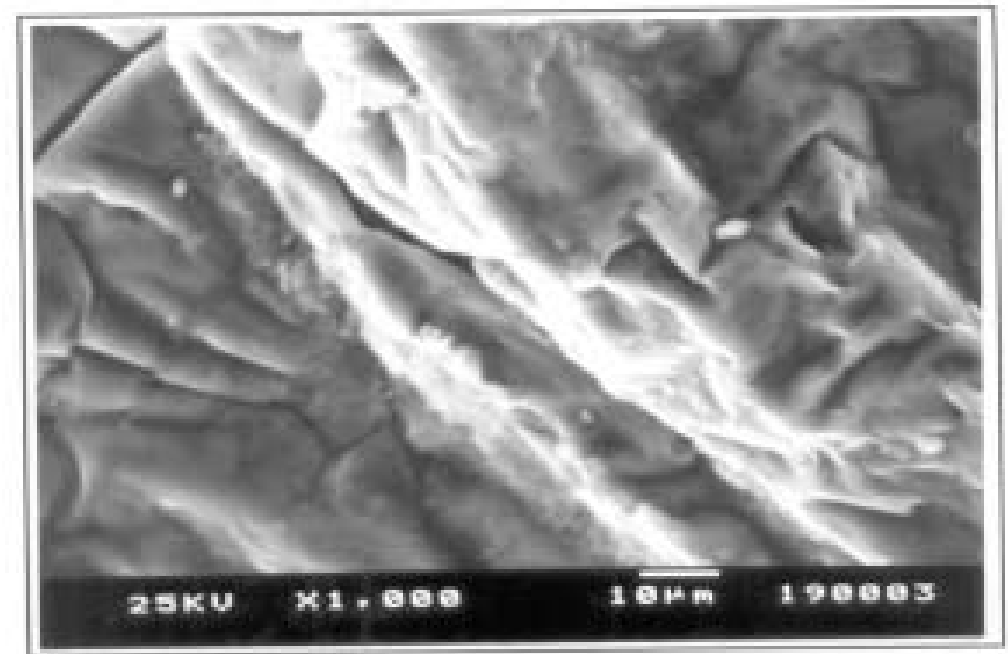

Figure 4: Secondary electron micrograph old oxide film defect initiated fatigue crack in filtered casting

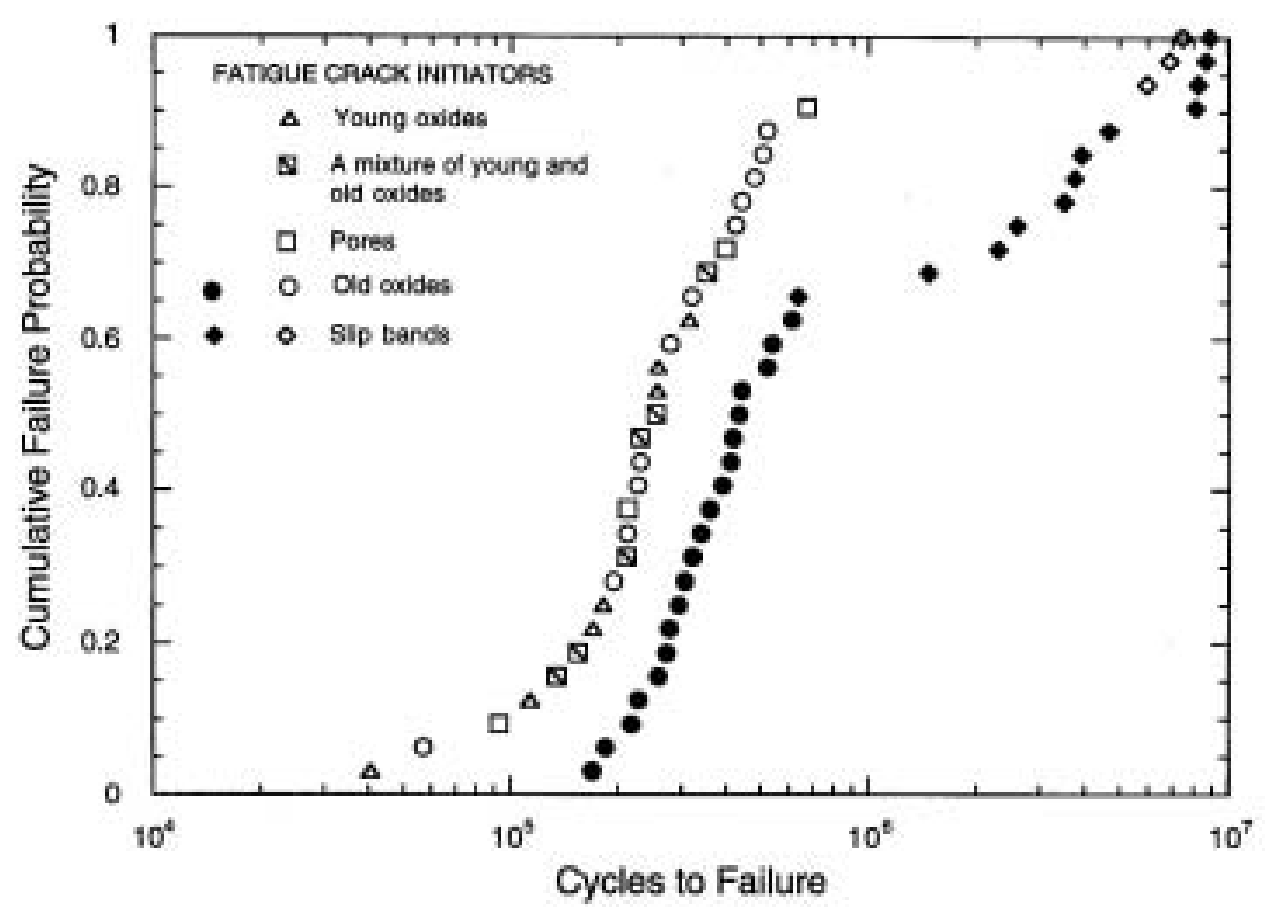

Figure 5: Correlation between fatigue crack initiators and fatigue life distributions for unfiltered (open symbols) and filtered (solid symbols) castings 
Effect of Multiple defect Distributions on Weibull analysis of fatigue life

The fatigue life data in relation to multiple defect types that initiated fatigue cracks are analysed statistically using Weibull statistical distribution functions. Best-fit statistical parameters are determined to describe the effects of old oxides, mixed (young and old) oxides, micro-pores and bubbles, and slip mechanisms.

Linear equation of the two-parameter Weibull distribution for a single distribution (Equation (1)) was first applied to describe the fatigue life data obtained from the castings. The best failure probability estimator [9], which is $F_{j}=(j-0.5) / n$, where $j$ is the ranked position of the specimen fatigue life in that set of casting, and $n$ is the total number of specimens, was also used. Though it has been recently shown that the optimal probability estimator varies with the sample size [10], the error found on the probability estimator as proposed in reference 9 is not significant.

A Weibull plot of $\ln \left[\ln \left(1 /\left(1-F_{w}\right)\right]\right.$ versus $\ln (N)$ for a single Weibull distribution is shown in Figure 6. It was found that the Weibull parameters associated with filtered castings are a Weibull modulus of 0.8 and a characteristic fatigue life of $16 \times 10^{5}$ cycles, and those associated with unfiltered castings are a Weibull modulus of 0.9 and characteristic fatigue life of $5.9 \times 10^{5}$ cycles. Figure 6 also shows that the fatigue life data points do not plot linearly as would be expected of data distributed in the form of a Weibull single defect distribution.

This indicates that either the data is distributed in a nonWeibullian manner or there is more than one defect type

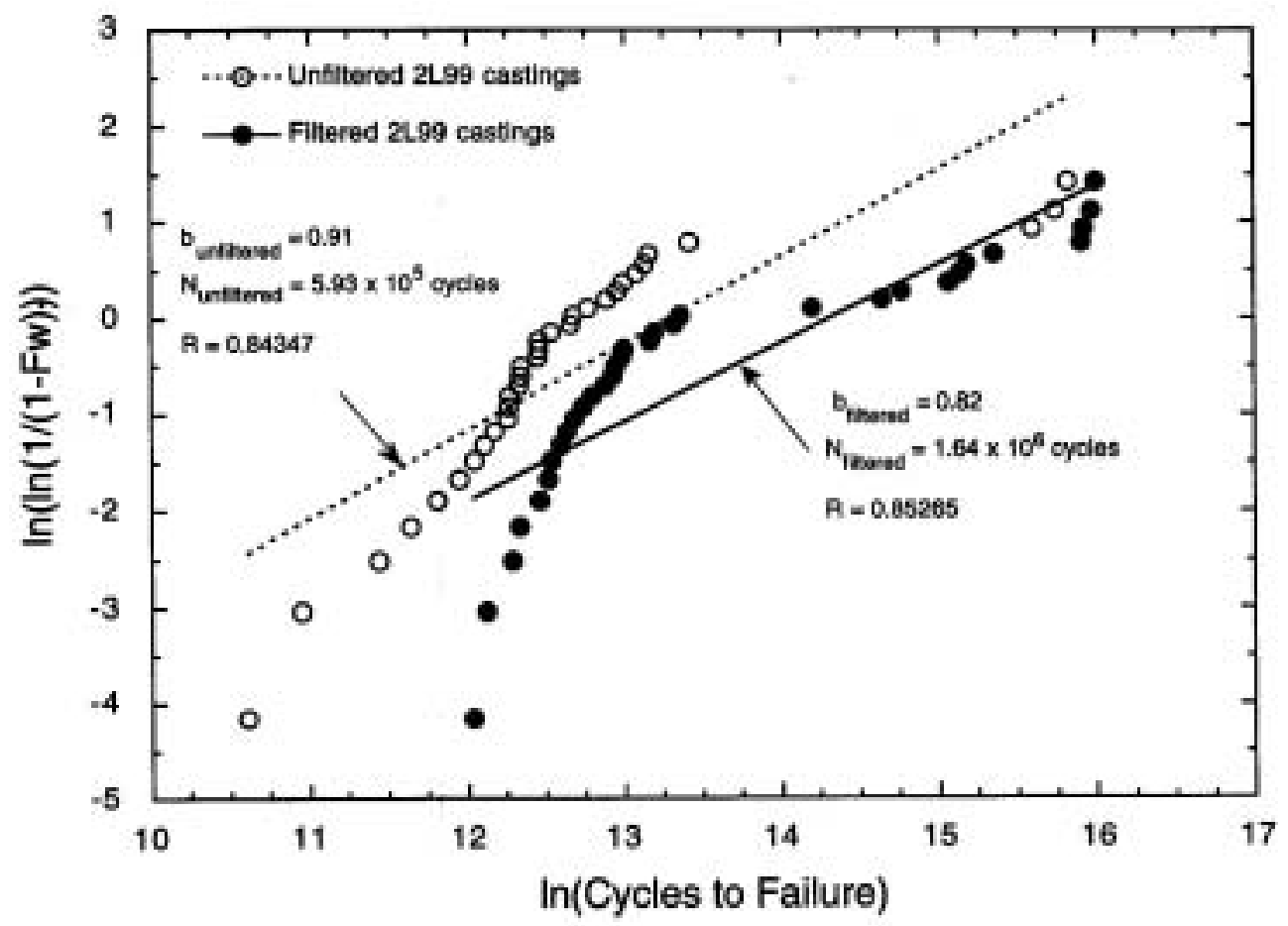

Figure 6: Two-parameter Weibull plot for fatigue life distributions of filtered and filtered castings, assuming a single defect distribution in castings 
competing to cause fatigue failure. The latter alternative is confirmed by the fractographic observations, with multiple fatigue crack initiators being identified. In the case of the filtered castings the competing mechanisms of crack initiation were old oxide film defects and slip, and for the unfiltered castings they were young oxides, a mixture of young and old oxides, pores associated with oxide films, and slip.

Based on the fractographic observations a statistical distribution for the action of multiple defect types was applied to each dataset of castings. Two- and threeparameter Weibull models for concurrent, mutually exclusive and partially concurrent double defect distributions were used to describe the fatigue life behaviour of the castings. Of these statistical distributions the two- and three-parameter partially concurrent Weibull models were found to give the best fit (Figures 7, 8, 9, and 10). This is understandable because, whenever a casting is manufactured which is free of casting defects, slip mechanisms will have to operate, whereas a fraction of the specimens were observed to contain oxide film defects which initiated failure. In the small volumes of material tested this is plausible, whereas the sample size increases the probability of an oxide film defects being present increase. This implies that the term $a$ in equation (5) is volume dependent.

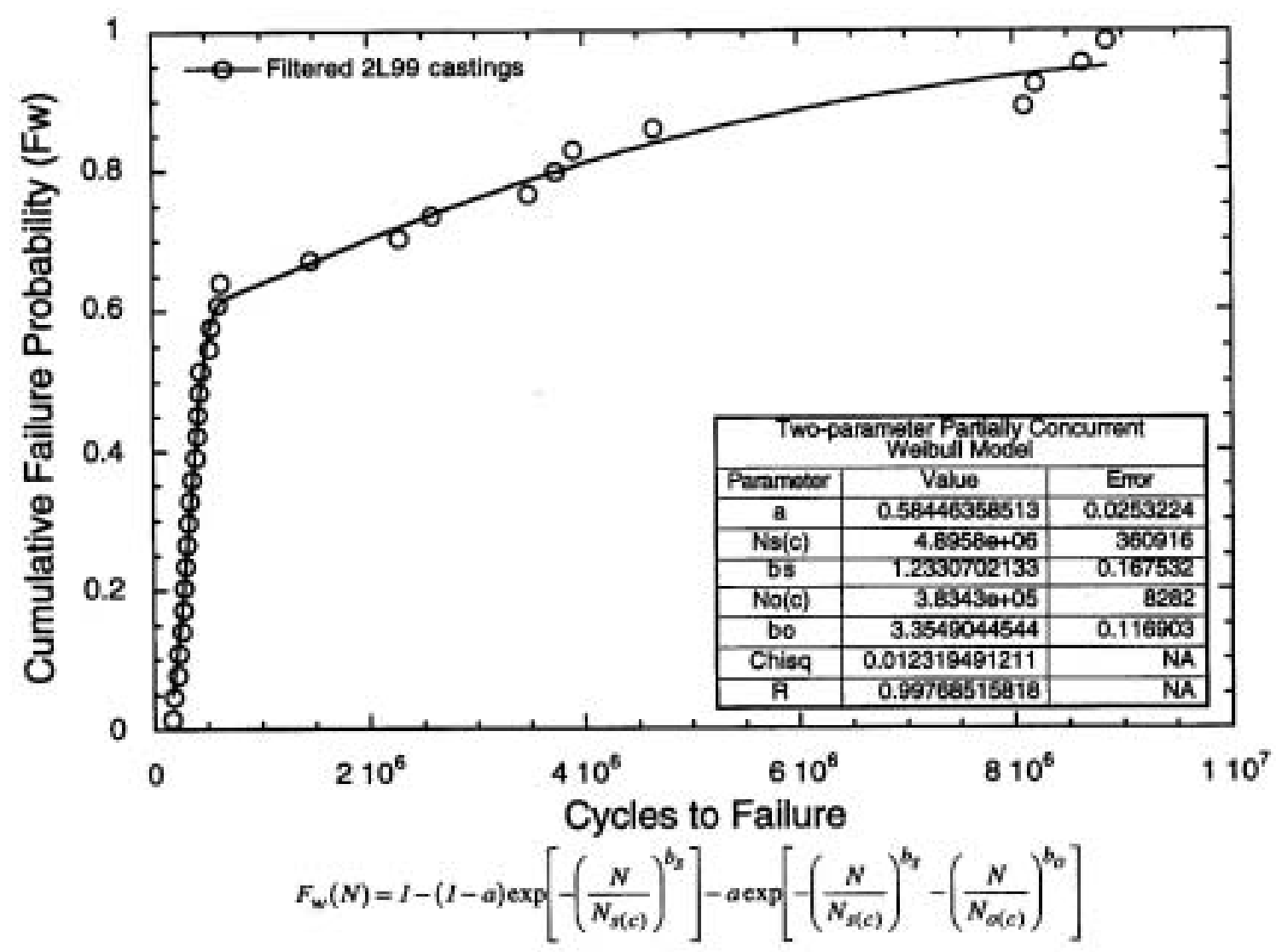

Figure 7: Two-parameter partially concurrent Weibull model for fatigue life distributions of filtered castings 


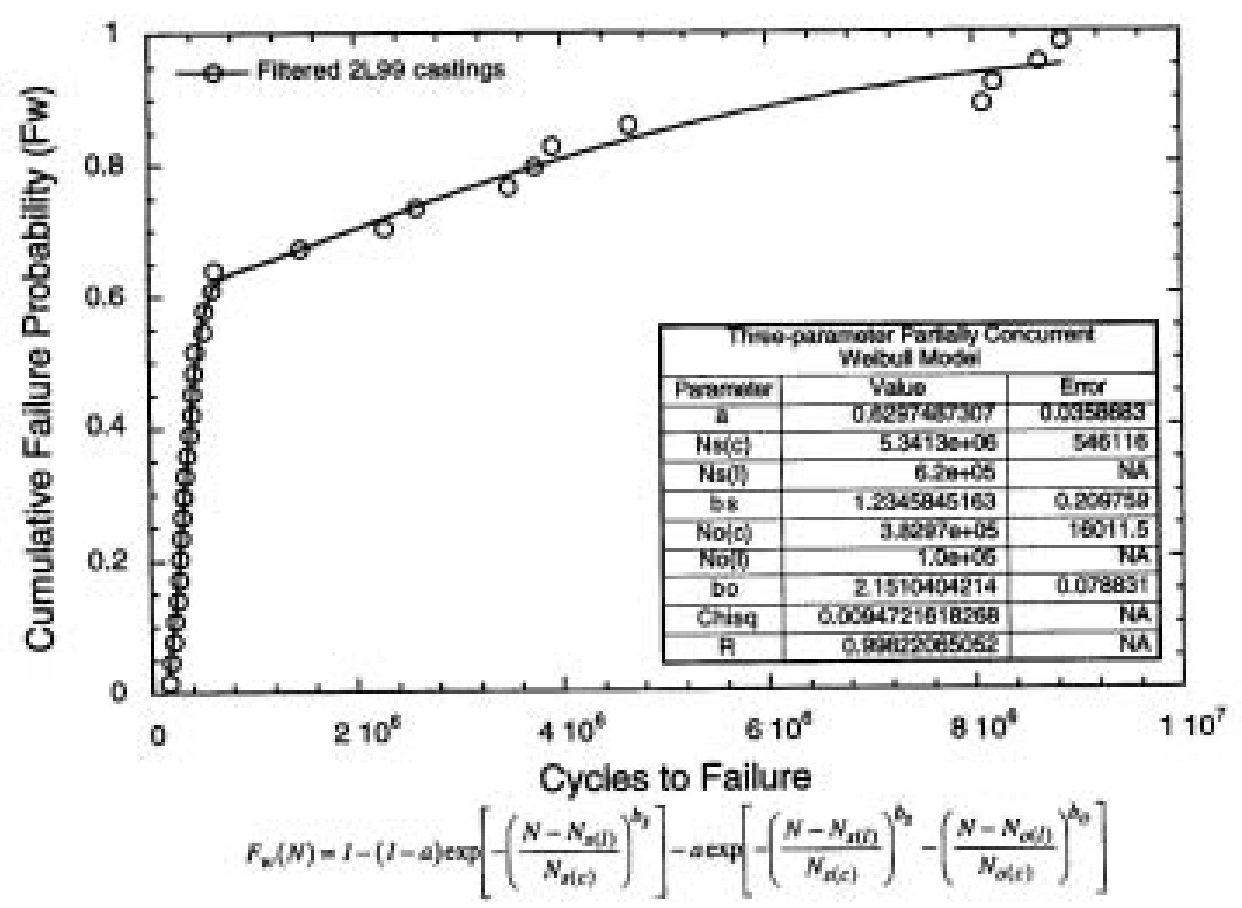

Figure 8: Three-parameter partially concurrent Weibull model for fatigue life distributions of filtered castings

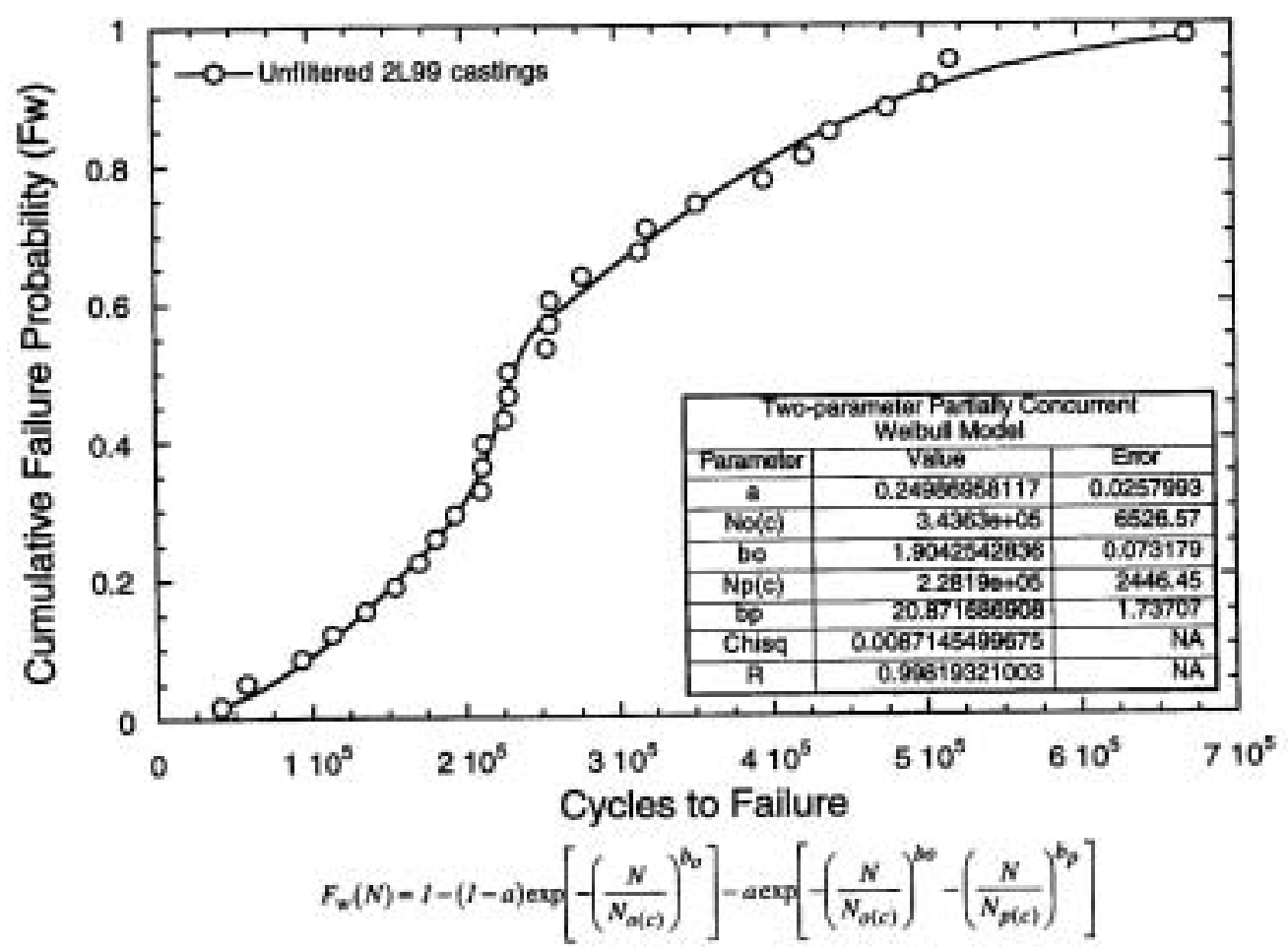

Figure 9: Two-parameter partially concurrent Weibull model for fatigue life distributions of unfiltered castings 
Table 1: The best-fit parameters as predicted by the two-parameter partially concurrent Weibull model for fatigue life distributions of unfiltered and filtered castings

\begin{tabular}{|c|c|c|c|c|}
\hline \multirow[b]{2}{*}{ Statistical parameters } & \multicolumn{2}{|c|}{ Fatigue crack initiators in } & \multicolumn{2}{|c|}{ Fatigue crack initiators in } \\
\hline & $\begin{array}{l}\text { Old oxide } \\
\text { film defects } \\
\text { (o) }\end{array}$ & $\begin{array}{c}\text { Slip } \\
\text { mechanis ms } \\
\text { (s) }\end{array}$ & $\begin{array}{l}\text { Young and } \\
\text { old oxide film } \\
\text { defects (o) }\end{array}$ & $\begin{array}{c}\text { Pores } \\
\text { attached to } \\
\text { oxide films } \\
\text { (p) }\end{array}$ \\
\hline $\begin{array}{l}\text { Characteris tics fatigue life, } \\
N_{c} \text { (cycles) }\end{array}$ & $3.8 \times 10^{5}$ & $4.9 \times 10^{6}$ & $3.4 \times 10^{5}$ & $2.3 \times 10^{5}$ \\
\hline W eibull modulus, $b$ & 3.4 & 1.2 & 1.9 & 20.9 \\
\hline $\begin{array}{l}\text { Fraction of specimen both } \\
\text { oxide defects and slip } \\
\text { mechanis m occurred, } a\end{array}$ & 0.58 & & \multicolumn{2}{|c|}{ Not applicable } \\
\hline $\begin{array}{l}\text { Fraction of specimen only } \\
\text { slip mechan is m occurred, } \\
(1-a)\end{array}$ & 0.42 & & \multicolumn{2}{|c|}{ Not applicable } \\
\hline $\begin{array}{l}\text { Fraction of specimen both } \\
\text { oxide defects and pores } \\
\text { occurred, } a\end{array}$ & $\begin{array}{c}\text { Not } \\
\text { applicable }\end{array}$ & & \multicolumn{2}{|c|}{0.25} \\
\hline $\begin{array}{l}\text { Fraction of specimen only } \\
\text { oxide defects occurred, } \\
\text { (1-a) }\end{array}$ & $\begin{array}{c}\text { Not } \\
\text { applicable }\end{array}$ & & \multicolumn{2}{|c|}{0.75} \\
\hline Regression coefficient, $R$ & 0.99769 & & \multicolumn{2}{|c|}{0.99819} \\
\hline
\end{tabular}


Table 2: The best-fit parameters as predicted by the three-parameter partially concurrent Weibull model for fatigue life distributions of unfiltered and filtered castings

\begin{tabular}{|c|c|c|c|c|}
\hline \multirow[b]{2}{*}{ Statistical parameters } & \multicolumn{2}{|c|}{ Fatigue crack initiators in } & \multicolumn{2}{|c|}{ Fatigue crack initiators in } \\
\hline & $\begin{array}{l}\text { Old oxide } \\
\text { film defects } \\
\text { (o) }\end{array}$ & $\begin{array}{c}\text { Slip } \\
\text { mechanisms } \\
\text { (s) }\end{array}$ & $\begin{array}{l}\text { Young and } \\
\text { old oxide film } \\
\text { defects (o) }\end{array}$ & $\begin{array}{l}\text { Pores } \\
\text { attached to } \\
\text { oxide films } \\
\text { (p) }\end{array}$ \\
\hline $\begin{array}{l}\text { Characteristics fatigue life, } \\
N_{c} \text { (cycles) }\end{array}$ & $3.8 \times 10^{5}$ & $5.3 \times 10^{6}$ & $3.3 \times 10^{5}$ & $2.3 \times 10^{5}$ \\
\hline Weibull modulus, $b$ & 2.2 & 1.2 & 1.6 & 23.2 \\
\hline $\begin{array}{l}\text { Fatigue life, } N_{l} \text {, below } \\
\text { which no failures occur } \\
\text { (cycles) }\end{array}$ & $1.0 \times 10^{5}$ & $6.2 \times 10^{5}$ & $4.0 \times 10^{4}$ & $5.0 \times 10^{4}$ \\
\hline $\begin{array}{l}\text { Fraction of specimen both } \\
\text { oxide defects and slip } \\
\text { mechanis m occurred, } a\end{array}$ & & 63 & Not app & licable \\
\hline $\begin{array}{l}\text { Fraction of specimen only } \\
\text { slip mechanis m occurred, } \\
(1-a)\end{array}$ & & 27 & Not app & licable \\
\hline $\begin{array}{l}\text { Fraction of specimen both } \\
\text { oxide defects and pores } \\
\text { occurred, } a\end{array}$ & Not ap & licable & 0.2 & \\
\hline $\begin{array}{l}\text { Fraction of specimen only } \\
\text { oxide defects occurred, } \\
\text { (1-a) }\end{array}$ & Not ap & licable & 0.7 & \\
\hline Regression coefficient, $R$ & 0.9 & 822 & 0.99 & 757 \\
\hline
\end{tabular}

* Sample size, $n=32$ 
Results of the partially concurrent Weibull analyses are shown in Figures 7 and 8 for filtered castings and in Figures 9 and 10 for unfiltered castings. The best-fit parameters for the two- and three-parameters partially concurrent Weibull models are listed in Tables 1 and 2 respectively. The suffixes $o, s$ and $p$ in Figures 7, 8, 9 and 10 as well as in Tables 1 and 2 relate to the actions of oxide film defects (old oxides or a mixture of young and old oxides), slip mechanisms and pores attached to oxide films respectively. The other suffixes that appear in the Figures and Tables are $c$ for characteristic fatigue life and $l$ for fatigue threshold below which no failure occurs (three parameter).

The two-parameter partially concurrent Weibull analysis on fatigue life data set of the filtered castings shows an agreement between the fractographic observations of fatigue crack initiators and the statistically derived proportion of specimens failing as a result of old oxide film defects. However, the three-parameter partially concurrent Weibull model shows a better agreement between the observed and derived statistical proportions. The fractographic analysis found $62 \%$ of specimens failed from cracks initiated by old oxides. This compares with the two-parameter Weibull statistical analysis which predicted $58 \%$ of specimens failed from entrained oxides and the three-parameter Weibull statistical analysis which gave the even more accurate prediction of $63 \%$.

In addition, the two-parameter Weibull model predicts a characteristic fatigue life of $3.8 \times 10^{5}$ cycles associated with old oxide and that associated with slip mechanisms to be $4.9 \times 10^{5}$ cycles. However, the action of the old oxide films is associated with less scatter in fatigue life and this manifested itself as a higher Weibull modulus of 3.4 compared to 1.2 for slip. On the other hand, the threeparameter Weibull model predicts a characteristic fatigue life of $3.8 \times 10^{5}$ cycles and a Weibull modulus of 2.2 associated with old oxide, and those associated with slip to be $53 \times 10^{5}$ cycles and 1.2 respectively. Furthermore, the three-parameter Weibull model predicts a fatigue life threshold of $1.0 \times 10^{5}$ cycles related to old oxide and that of $6.2 \times 10^{5}$ cycles related to fatigue failures initiated by slip mechanisms. Both the lower characteristic fatigue life and fatigue life threshold compared to those of slip mechanisms reflect the far more serious effect of the old oxide film defects in the filtered castings. It can be concluded that both the two- and three-parameter partially concurrent Weibull models correctly described the fatigue life distribution for the filtered castings, though the threeparameter Weibull model is surely the more realistic and more accurate.
The two-parameter partially concurrent Weibull model was also found to fit accurately the fatigue life data of the unfiltered castings (Figure 9). However, the Weibull bestfit parameters associated with pores attached to oxide films do not appear to describe satisfactorily the fractographic examination results. The very high Weibull modulus of 20.9 indicates less scatter of the fatigue data associated with pores and implies therefore that pores related failures should be concentrated in the region of their characteristic fatigue life of $2.3 \times 10^{5}$ cycles. When these fatigue life data set are further analysed by the three-parameter partially concurrent Weibull model (Figure 10), similar Weibull parameters associated with pores are obtained (Table 2), a Weibull modulus of 23.2 and characteristic fatigue life of $3.3 \times 10^{5}$ cycles. However, the fractographic results showed distribution of pores throughout the data set possibly due to over a much wider range of fatigue lives. It is therefore concluded that either the two- or threeparameter partially concurrent Weibull distribution models could not correctly describe the fatigue life distribution for the unfiltered castings.

\section{CONCLUSIONS}

Three types of defects were observed to initiate fatigue cracks in the castings: (i) young oxide films which are originated from turbulence in the mould, (ii) pores which are associated with young oxide films, and (iii) old oxide films are assumed to be carried into the castings from the melting furnace. Each defect type played a different role on influencing the fatigue life of the castings. The majority of fatigue cracks initiated at young oxide film defects were associated with lower fatigue lives than fatigue cracks initiated at old oxide film defects.

Competing mechanisms of fatigue crack initiation in the unfiltered castings were a combination of young and old oxide film defects, pores associated with oxide films, and slip. Those in the filtered castings were old oxide film defects and slip.

Two- and three-parameter partially concurrent Weibull model correctly describe the fatigue life of distributions in filtered castings whose failures initiated at old oxide film defects and by slip mechanisms. The two-parameter concurrent Weibull statistical model predicated competition between slip and old oxide initiation of cracking in $58 \%$ of the specimens, whereas the threeparameter partially concurrent Weibull model predicted $63 \%$ of the specimens. The fractions of failures predicted by the models are close to the $62 \%$ of specimens experimentally observed to have failed from cracks initiated at old oxide film defects. 
Although the two- and three-parameter partially concurrent Weibull models were found to fit accurately the fatigue life distribution of the unfiltered castings, the fractions of failures predicted by the models are not in agreement with the fractions of unfiltered castings experimentally observed to have failed from cracks initiated at a mixture of young and old oxide film defects and pores associated with oxide films.

\section{ACKNOWLEDGEMENT}

The author is grateful to of the University of Birmingham through the School of Metallurgy and Materials and IRC for the provision of research facilities and other supports and University of Dar es Salaam though the German Agency for Technical Co-operation for the financial support of the research work.

\section{REFERENCES}

1. N.R. Green, and J. Campbell, 1994. "Influence of Oxide Film Filling Defects on the Strength of Al-7Si-Mg Alloy Castings," AFS Transactions, 102, pp. 341 347.

2. J. Campbell, 2003. Casting, Butterworth-Heinemann, Oxford, Second Edition.

3. M.J. Couper, A. E. Neeson and J.R. Griffiths 1990. "Casting Defects and the Fatigue Behaviour of an Aluminium Casting Alloy," Fatigue and Fracture Engineering Materials Structure, 13(3), pp. 213 227.
4. C. Nyahumwa, N.R. Green, and J. Campbell, 1998. "Effect of Mold-Filling Turbulence on Fatigue Properties of Cast Aluminium Alloys," AFS Transactions, 106, pp. $215-223$.

5. W. Weibull, 1951. "Statistical Distribution Function of Wide Applicability," J. of Applied Mechanics, 18(3), pp. $293-297$.

6. C.A. Johnson, 1983. "Fracture Statistics of Multiple Flaw Distribution," J. of Fracture Mechanics of Ceramics, 5, pp. $365-386$.

7. Y. Murakami, 1994. "Inclusion Rating by Statistics of Extreme Values and Quality Control of Materials," J. of Research of the National Institute of Standards and Technology, 99, pp. $345-351$.

8. E.J. Gumbel, 1967. "Statistics of Extremes," Columbia University Press, New York, (1967).

9. A. Khalili, and K. Kromp, 1991. "Statistical Properties of Weibull Estimators," J. of Materials Science, 26, pp. $6741-6752$.

10. D. Wu, G. Lu, H. Jiang, and Y. Li, 2004. "Improved Estimation of Weibull Parameters with the Linear Regression Method," J. American Ceramic Society, 87(9), pp. 1799-1802. 